\title{
Differential hemodynamic characteristics of high- resistance vs. high-flow type of pulmonary artery hypertension revealed by phase-contrast MRI
}

\author{
Ming-Ting $\mathrm{Wu}^{1,2^{*}}$, Chen-Hua Wang ${ }^{3}$, Chin-Chang Cheng ${ }^{2,4}$, Wei-Chun Huang ${ }^{2,4}$, Ming-Jyh Chern ${ }^{3}$ \\ From 18th Annual SCMR Scientific Sessions \\ Nice, France. 4-7 February 2015
}

\section{Background}

Phase-contrast MR (PC-MR) is able to show the hemodynamic features of pulmonary artery hypertension (PAH) in comparison to normal subjects. We aimed to further characterize the subtypes of high-flow vs. high-resistance PAH using 3D PC-MR.

\section{Methods}

Total 68 subjects were enrolled, including: Group 1, 19 normal control ( $38.5 \pm 16$ years old, $M / F=2 / 17)$; Group 2, 15 high-flow type $\mathrm{PAH}$, related to untreated simple congenital heart disease $(39.7 \pm 17.9$ years old, $M / F=4 / 11)$ and Group 3, 34 high-resistance type PAH $(47.9 \pm 18.5$ years old, $M / F=6 / 28)$, including idiopathic PAH $(\mathrm{N}=15)$ and SLE-related PAH $(\mathrm{N}=19)$.

MRI was performed on 1.5T scanner. 2D and 3D PCMR on the cross-section and 4D PC-MR on longitudinal axis of main pulmonary artery were performed. Data analysis was performed by Flow Quantification Analysis (MedVoxel, Vancouver, CA) for area and distensibility, flow rate and velocity, accelerative time and pulse wave velocity (PWV). An institute- developed program via MatLab $^{\mathrm{TM}}$ and tecplot ${ }^{\mathrm{TM}}$ was used for visualization and quantification of the number and duration of vortex, and the pressure gradient and pulmonary vascular resistance (PVR).

Echocardiography estimated pulmonary artery pressure gradient (echoPASP) were performed for all subjects. Right heart catheterization for mean pulmonary artery pressure (meanPAP) was performed for Group 2 and 3 within 3 months of PC-MR.

\section{Results}

As compared to Group 1, MPA of Group 2 and 3 showed larger cross-sectional area $(\mathrm{P}<0.001)$, decreased distensibility $(\mathrm{P}=0.001)$, slower flow velocity $(\mathrm{P}<0.001)$, faster $\mathrm{PWV}(\mathrm{p}=0.005)$, with more $(\mathrm{P}<0.001)$ and longer duration $(\mathrm{P}=0.030)$ of vortex and higher PVR $(\mathrm{P}<0.001)$. (Table).

Compared to Group 2, Group 3 had lower flow rate $(\mathrm{P}=0.002)$, shorter accelerative time $(\mathrm{P}=0.003)$ and higher PVR $(\mathrm{P}=0.018)$.(Table).

With multiple linear regression model, we found that vortex (number and duration) and PWV of MPA predicted well of meanPAP in Group $3(\mathrm{R}=0.821)$, while only moderately in Group $2(\mathrm{R}=0.625)$. With adding the distensibility of MPA, the prediction of mean PAP improved significantly ( $\mathrm{R}=0.625$ to 0.978 ) in Group 2, while only marginally in Group 3 ( $R=0.821$ to 0.873 ).

\section{Conclusions}

PC-MR revealed overt different hemodynamics of PAH as compared to the normal subjects. In addition, several hemodynamic characteristics were distinct between the high-resistance type and high-flow type PAH. The increase of number and duration of vortical flow reflected the increase of pressure in high-resistance $\mathrm{PAH}$, while the MPA distensibility reflected the hyperdynamic flow in high-flow PAH. The discrepancy disclosed the different underlined pathophysiology between the subtypes of PAH.

\section{Funding}

Grant: NSC 100-2314-B-010 -045 -MY3, Taiwan.

${ }^{1}$ Radiology, Kaohsiung Veterans General Hospital, Kaohsiung, Taiwan Full list of author information is available at the end of the article 
Table 1 Hemodynamic characterisitcs of main pulmonary artery in the three groups

\begin{tabular}{cccc}
\hline & Group 1 & Group 2 & Group 3 \\
\cline { 2 - 4 } & Normal & High-flow PAH & High-resistance PAH \\
\cline { 2 - 4 } & $\mathrm{N}=19$ & $\mathrm{~N}=15$ & $\mathrm{~N}=34$ \\
\hline Main pulmonary artery & Mean \pm SD & Mean \pm SD & Mean \pm SD \\
\hline echoPASP, $\mathrm{mmHg}$ & $30.3 \pm 15.6$ & $74.0 \pm 35.8$ & $70.5 \pm 29.2$ \\
\hline mean PAP, $\mathrm{mmHg}$ & & $48.1 \pm 27.8$ & $41.7 \pm 14.5$ \\
\hline area, max, cm2 & $6.6 \pm 1.7$ & $14.4 \pm 5.6$ & $12.3 \pm 5.0$ \\
\hline distensibility, \% & $24.9 \pm 8.7$ & $17.9 \pm 11.8$ & $14.4 \pm 9.2$ \\
\hline flow rate, $\mathrm{mL} / \mathrm{min}$ & $5791.2 \pm 1286.0$ & $4586.0 \pm 1580.6$ \\
\hline peak velocity, cm/s & $46.7 \pm 7.6$ & $23.3 \pm 11.4$ \\
\hline accelerate time, $\mathrm{ms}$ & $232.0 \pm 25.3$ & $171.2 \pm 39.9$ \\
\hline Pulse wave velocity, $\mathrm{m} / \mathrm{s}$ & $2.0 \pm 1.0$ & $211.3 \pm 44.5$ & $3.4 \pm 1.5$ \\
\hline vortex, number & $3.5 \pm 3.0$ & $3.5 \pm 1.9$ & $13.0 \pm 8.2$ \\
\hline vortex, duration, $\mathrm{s}$ & $0.17 \pm 0.13$ & $12.1 \pm 8.2$ & $0.22 \pm 0.09$ \\
\hline resistance (PVR), dyne.s.cm-5 & $16.3 \pm 6.6$ & $0.28 \pm 0.13$ & $39.9 \pm 21.0$ \\
\hline
\end{tabular}

\section{Authors' details}

'Radiology, Kaohsiung Veterans General Hospital, Kaohsiung, Taiwan. ${ }^{2}$ Faculty of Medicine, School of Medicine, National Yang Ming University, Taipei, Taiwan. ${ }^{3}$ Mechanical Engineering, National Taiwan University of Science and Technology, Taipei, Taiwan. ${ }^{4}$ Cardiovascular Medicine, Kaohsiung Veterans General Hospital, Kaohsiung, Taiwan.

Published: 3 February 2015

\section{doi:10.1186/1532-429X-17-S1-069}

Cite this article as: Wu et al:: Differential hemodynamic characteristics of high-resistance vs. high-flow type of pulmonary artery hypertension revealed by phase-contrast MRI. Journal of Cardiovascular Magnetic Resonance 2015 17(Suppl 1):O69.

\section{Submit your next manuscript to BioMed Central} and take full advantage of:

- Convenient online submission

- Thorough peer review

- No space constraints or color figure charges

- Immediate publication on acceptance

- Inclusion in PubMed, CAS, Scopus and Google Scholar

- Research which is freely available for redistribution

Submit your manuscript at www.biomedcentral.com/submit 